\title{
How do the design features of health hackathons contribute to participatory medicine?
}

\author{
Karen Day \\ School of Population Health \\ The University of Auckland \\ New Zealand. \\ k.day@auckland.ac.nz
}

\section{Gayl Humphrey}

National Institute for Health Innovation

The University of Auckland

New Zealand

\section{Sophie Cockcroft \\ UQ Business School \\ University of Queensland \\ Australia}

\section{Abstract}

The Hackathon concept is attracting interest as a vehicle for participatory development in both Health and Information systems. Publically available datasets, cloud based data storage, and increasingly sophisticated analytical methods, combined with user friendly development tools for mobile devices are inspiring innovation in the participatory medicine space. This has the potential to disrupt traditional methods and deliver solutions more rapidly, and in a form more likely to meet requirements. In health applications this involves putting the patient and their supports at the centre of design. This work contributes to solving the challenges involved in bringing a diverse cohort of designers, developers, problem owners, healthcare providers, patients, and citizens together to solve user-driven self-care problems using technology. We use a descriptive case study approach focussing on two weekend-long hackathons dubbed "Health Hackathon: Solving Self-care". We gather thick data from multiple sources according to the process defined by Geertz (1994) first, to provide a rich picture of the role of hackathons in participatory medicine and second, to contribute evidence to the practise of running a hackathon. Some key originalities of our work include seeking more candid responses via selfserve interviews. Through this, controversially, we noted a marked emphasis on the creative process over concerns for privacy and ethics around the personal data cloud created by hackathon products. We build on existing theories of participatory medicine and emerging methodologies for conducting hackathons to provide evidence of the efficacy of the hacking approach both in terms of outcome and team dynamics. Through interviews, observation, twitter feeds and a pre-survey, we identify a number of success factors including (1) group size, (2) maturity of the idea, (3) level of involvement of a mentor, and (4) involvement of students. In addition we identify five skills identified by successful health hackathon participants; knowledge, patient focussed skills, analytical skills, software design skills and professional perspective. In common with previous studies we find that there are considerable social benefits that accrue in running a hackathon. Participants meet new people and learn first-hand of the challenges and opportunities provided by the skill sets and work environments of others. This work builds on the existing body of research concerning hackathons and in particular work in the context of participatory medicine

Keywords Hackathon; self-care; participatory medicine; information systems design

\section{Introduction}

Health is everybody's business. People are living longer than ever before, but more people are now dealing with health issues that persist and for which there is no current cure, such as 
diabetes, asthma, and cardiovascular disease. Models of care are emerging and evolving, the most recognised of which is the Chronic Care Model (CCM) (Wagner, Davis, Schaefer, Von Korff, \& Austin, 2002). The CCM claims that effective care is based on 'productive interactions' between the people providing care and those needing and accessing it. Widespread use of this model has demonstrated improvements in the health of people with long term health issues (Gee, Greenwood, Paterniti, Ward, \& Miller, 2015; Stellefson, 2013). The model has been adjusted to incorporate ehealth components (Gee et al., 2015).

Participatory medicine takes the CCM a step further, and redefines the "productive interactions' relationship between user and provider of healthcare services. Frydman (2010) defines participatory medicine on the e-patients.net website as

“... a movement in which networked patients shift from being mere passengers to responsible drivers of their health, and in which providers encourage and value them as full partners."

Patients are no longer simply interacting productively with healthcare providers, many are 'driving' the interactions and taking charge of their health by using information sources on the Internet and collecting and using data for self-care purposes (Auffray, Charron, \& Hood, 2010; Hood \& Auffray, 2013). This is evidenced by the Quantified Self movement in which people collect data about themselves (often with tools they create) to improve their self-awareness and decision making (Bowen et al., 2013; Swan, 2012). Swan (2012) argues that crowdsourcing of data from populations and self-tracking by individuals should become part of the foundation of the future of health care. The increased involvement of all stakeholders, and ubiquity of information systems as integral parts of the health care system, raise opportunities for participatory medicine.

How do hackathons fit in this new ecosystem? Health hackathons bring together participants from all parts of the healthcare system as described in the CCM, as well as giving 'patients' ${ }^{1}$ an opportunity to lead and fully participate in software innovation development. Hackathons are weekend/week long events in which teams of people with mixed skills and backgrounds form groups and work intensively on a technology solution to a problem (Chowdhury, 2012).

Our research question is, 'How do the design features of health hackathons contribute to participatory medicine?'

The paper proceeds as follows. We discuss participatory medicine and its pivotal role in modern healthcare. We then explore how Information Systems for self-care are impacted by this. Focussing on the health domain we then examine the evolving methodology implicit in hackathons. In the remaining sections the research design is described we present the findings via an in depth analysis of the thick data (Geertz, 1994) generated by the process. Finally, we discuss our hackathon process in the context of prior studies and make suggestions for success factors and in the conclusion describe the hackathon process can contribute to participatory design and participatory medicine in the future.

\section{Background}

\subsection{Participatory medicine}

Participatory medicine puts citizens in charge of their health (Auffray et al., 2010; Frydman, 2010; Hood \& Auffray, 2013), i.e. as active participants in data collection and decision making about their own health. This is more than the relationship implied in the CCM, of proactive providers and informed responsive patients (Gee et al., 2015; Wagner et al., 2002). It extends the patient-clinician relationship from productive interactions to incorporate activities outside

\footnotetext{
${ }^{1}$ In the CCM people interacting with providers of healthcare services are called 'patients'. For the purpose of this article, they will be referred to as 'citizens' in the spirit of participatory medicine, were the person accessing and using healthcare services is actively involved in the design, delivery, and use of such services.
} 
the clinician's workplace, e.g. access to vast amounts of health information on the Internet that citizens use to make their own healthcare decisions (Bragazzi, 2013; Flores, Glusman, Brogaard, Price, \& Hood, 2013). Data is collected about lifestyle, personal health indicators, e.g. blood pressure monitoring, and any other data of interest, as evidenced by the range of data collected by members of the Quantified Self. This extends clinicians' roles to include supervision and coaching of citizens as they learn about their own diagnostic tests, treatments, and responses to treatments, in order to make informed decisions about their health (Hood \& Auffray, 2013).

The context of participatory medicine is systems. Systems medicine incorporates predictive, preventive, personalised, and participatory principles (also referred to as 'P4') (Hood \& Auffray, 2013). Bragazzi (2013) proposes two additional principles - psychocognitive and public - describing the importance of personal responses to health, and also how people make their data public in pursuit of benefits for others. He includes psychocognitive and public components of P6 medicine as 'community, collaboration, self-caring, co-creation, coproduction, and co-development using technologies delivered via the Internet' (pg 357). Once diseases are seen in the context of a biological and social system, they can be predicted and prevented. This requires big data analytics, i.e. the analysis of very large, often unstructured data from multiple sources. Consequently, diseases and patients can be stratified, and early and accurate diagnosis and prevention are more accessible. People are deemed to have a 'personal data cloud' about their own health profile (Flores et al., 2013), which can be pooled with the clouds of other people and mined for health and care planning, and service delivery. Diversity, multiple dimensions of data, sourced from many people, provide 'thick data' (Geertz, 1994) for diagnosis and care planning, enabling the potential for citizens to plan their own healthcare. This cloud enables personalisation of healthcare, in the form of accurate stratified diagnosis and intervention.

The ability to collect, collate, and analyse large amounts of highly detailed data, has enabled the view of 'network of networks' of biological phenomena. This 'network of networks' concept is in turn applied socially to people using the Internet. Social media and other facilities on the Internet, such as Google and Facebook, have enabled networks of people to form and collectively respond to healthcare needs and thereby be collectively responsive to disease and wellness, e.g. peer to peer groups such as patientslikeme (Bragazzi, 2013; Flores et al., 2013; Hood \& Auffray, 2013). Citizens are becoming 'active informed consumers interacting in digitally powered social networks' (Flores et al., 2013, pg 566). Consequently, citizens design and co-produce innovative technologies with or without healthcare and information systems professionals to collect and respond to data.

\subsection{Involving citizens in information systems design}

The software design process is complex, involving many stakeholders with different points of view and needs. Developing information systems typically involves four phases; planning, analysis, design, and implementation. The heart of the analysis phase is requirements elicitation: this is critical in health applications where user acceptance and usability are key issues. In recent years there has been an emphasis on user-centric design (Andersen, Bansler, Kensing, Moll, \& Nielsen, 2014; Pilemalm \& Timpka, 2008). In health care, the users are typically identified as clinicians and others who work in health services (Bahlol Rahimi, Vimarlund, \& Timpka, 2009). Traditionally the requirements of stakeholders (usually health and care professionals) are assessed using interviews, observation, document analysis and questionnaires (Dennis, Wixom, \& Roth, 2014; Shelly \& Rosenblatt, 2011). Often, to be expedient at project sign off, the final agreement on requirements places more weight on the inputs of budget holders and high level decision makers. The practice team (clinicians and managers in healthcare services) becomes somewhat distanced from the final design decisions of the information system they will be using in the future.

As a middle layer between healthcare management and consumers, information systems design in health has traditionally focussed on clinicians, such as doctors and nurses, and their information needs in carrying out their duties. Citizens are often overlooked as key 
stakeholders, even though the system development process can include consumer representatives (citizens). Citizens are usually outnumbered in the context of userdriven/focussed design. Nunes, Verdezoto, Fitzpatrick, Kyng, Gr, et al. (2015) found that many studies concerning the development of systems for self-care privileged a medical perspective. Leading on from this Nunes et al developed themes via a Grounded Theory literature review method that suggested further focus was needed on citizens' day to day lived experience, and in using the existing frameworks and networks of carers and support people that citizens have around them.

Participatory design is a type of sociotechnical design that advocates involvement of users throughout the development process and whilst it has not been widely adopted in healthcare environments it is gaining currency (Andersen et al., 2014; Ballegaard, Hansen, \& Kyng, 2008; Bowen et al., 2013; Cole-Lewis et al., 2016; De Silva, Burstein, Stranieri, Williams, \& Rinehart, 2013; Teixeira, Saavedra, Ferreira, Santos, \& IEEE, 2011). In a participatory medicine context, the inclusion of citizens in information systems design for self-care is becoming essential.

\subsection{The nature of hackathons}

Health hackathons have gained significant traction as sources of medical innovation globally (DePasse et al., 2014; Mantzavinou \& Ranger, 2014). Hackathons have the potential to deliver solutions where there are health discrepancies among citizens and where resources are limited. They are seen as a valuable way of discovering innovation for health care (Walker \& Ko, 2016). Chowdhury (2012) states that hackathons are a way for people (who would normally not be collaborating on a healthcare project) to collaborate and develop a solution, as a bottom-up form of change. In this way, citizens, healthcare professionals, and technology developers can be partners in the 'productive interactions' characteristic of the CCM. As the interactions are outside of the personal and private doctor-patient relationship, citizens are incorporated into the design space as equals.

Hackathons are inclusive and are not bounded by the conventions of traditional system development. The inclusive spirit of hackathons gives citizens a place in the design space. A hackathon is an event at which people create software solutions to real life problems, meeting and working with people and expertise otherwise not available (Chowdhury, 2012). The events are not always called hackathons, e.g. sometimes they are called boot camps. The event is announced (usually on the Internet), and people are invited to participate. There is no screening to select people with certain skills. There is no attempt to control who attends and what problems they want to solve, or what skills they bring (Jones, Semel, \& Le, 2015; Komssi, Pichlis, Raatikainen, Kindström, \& Järvinen, 2015). The only common attempt at control is to define the theme for a hackathon (Komssi et al., 2015). Briscoe and Mulligan (2014) describe different types of hackathon, classifying them broadly as techno-centric and focus-centric. The techno-centric hackathons are typified by the development of open source software. The focuscentric hackathon is usually socially oriented and demography specific. Focus-centric hackathons target software development to address or contribute to a social issue or a business objective, and are considered applied hackathons.

Hackathon event planning and the event itself follows a process. Komssi et al (2015) describe three stages: pre-hackathon, hackathon, and post-hackathon. The pre-hackathon period involves participants creating ideas and preparing pitches of their ideas, and building teams to bring to the hackathon. The hackathon stage involves intense hacking and building of a prototype, while the post-hackathon stage is the period in which the new technology matures and new relationships are developed. De Passe et al (2014) describe three stages that fit the Komssi et al (2015) description of the hackathon stage. In the first stage pain points are identified for solutions to be developed. This is followed by the development of teams who brainstorm the problem and possible solution/s, build a prototype (or minimum viable product), and present it for judges to determine the best product prototype. Anyone who is interested in an idea (pain point) that has been pitched is able to join/form a group. People discuss the idea with the person who presented it, make decisions about what skills are 
required, and what they have to offer, and then decide (tentatively at first) to join a group (Jones et al., 2015).

Hackathons have characteristics that identify the events and associated activities uniquely as hackathons. Hackathons are intensive weekend or day-long events. The primary purpose of a hackathon is to solve problems (Chowdhury, 2012; Komssi et al., 2015). Software is usually developed, although some organisations are using the hackathon model to achieve nonsoftware goals, e.g. the 'transformathons' used by the UK's National Health Service to stimulate rapid and deep change (NHS, 2016). Anyone can pitch an idea to solve a problem and anyone can offer to help design and develop a solution, i.e. hackathons are egalitarian (Chowdhury, 2012; Jones et al., 2015). Individuals usually pitch the ideas and self-organised groups usually work on the solutions (Jones et al., 2015). The development of a solution is treated as a competition in which the group with the best prototype wins (sometimes a monetary prize, sometimes mentoring and assistance with taking the product to market) (Angelidis et al., 2016; DePasse et al., 2014; Komssi et al., 2015).

Hackathons typically operate on an open invitation for people to develop solutions to problems in the form of open software, thus enabling open participation for anyone with an interest in a problem and or its solution. People bring skills, experience, and expertise that is usually not available in the everyday workplace, thus enabling new ways of thinking and doing that are not accessible in everyday work.

Health care has historically shifted from a paternalistic approach (where clinicians and other healthcare providers were privileged and patients were passive recipients of care) to a systems approach (Bragazzi, 2013). Similarly, the design of healthcare information systems has privileged clinicians and other healthcare providers, essentially ignoring the idea that the consumer/patient/citizen is also an end-user. To enable the cultural shift to the new systems medicine approach, patients (citizens) are encouraged to participate in and take charge of their own healthcare. Participatory medicine is part of systems medicine, which includes collecting data and using data analytics to explore so called "big data" (De Silva, Burstein, Jelinek, \& Stranieri, 2015) in order to provide preventive, predictive, participatory, public, and psychocognitive health care. Innovation involving information systems is essential for systems medicine to succeed. Hackathons have no rules - anyone who is interested can identify pain points and work in self-organised groups to solve problems with information systems innovations.

\section{3 'Health Hackathon: Solving Self-care' as case study}

We present a case study of a real world application of participatory health information system development. The case study consists of two hackathons collaboratively hosted by the University of Auckland, New Zealand, in collaboration with HiNZ (Health Informatics New Zealand), an organisation that represents health informaticians. The hackathons occurred on $13-15$ February, 2015, and 18 - 20 March, 2016. The topic for both hackathons was 'Health Hackathon: Solving Self-care' focussing on the citizen's (or patient's) perspective. Ethics approval for research on the hackathons was granted by the University of Auckland Human Participants Ethics Committee on 16/12/2014, reference number 013391.

A run sheet was designed for the weekend's schedule, based on the process described by Komssi et al (2015) and DePasse et al (2014) and hackathon hosts whom KD interviewed while planning the 2015 event, e.g. two UK NHS hackathon hosts ("NHS Hack Day," 2015). After the event opening, people were invited to pitch their ideas (pain points), groups formed during the course of the evening, and worked on their solution over the course of the weekend. All groups presented their prototype to a panel of judges and audience on Sunday afternoon. The hackathon was considered to be over after the four judges selected and announced the winner.

The hackathons began at $6.00 \mathrm{pm}$ on the Friday and continued until $4.00 \mathrm{pm}$ on the Sunday. Although the venue closed at $10.00 \mathrm{pm}$ each evening, participants took tasks home and 
continued working. The hackathon activities, schedule, and group dynamics and processes lent themselves to data collection for research purposes.

\section{Research design}

A hackathon follows the same process regardless of the topic (DePasse et al., 2014; Komssi et al., 2015), making available several opportunities for research data to be collected. Table 1 shows how these opportunities were used to gather data. Our multi-method approach aimed at triangulation, in which results overlaps from the different methods confirmed findings or presented different facets of the same phenomena (Morse, 2015). We chose multiple methods to give us thick multi-faceted descriptions (Geertz, 1994) especially if there was a low number of responses. We aimed to attract up to 120 participants for each hackathon. We collected data about the people and about the event.

\begin{tabular}{|l|l|l|l|l|}
\hline From the people & $\begin{array}{l}\text { About the } \\
\text { people }\end{array}$ & $\mathbf{2 0 1 5}$ & $\mathbf{2 0 1 6}$ & $\begin{array}{l}\text { About the } \\
\text { event }\end{array}$ \\
\hline Questionnaires: & $\begin{array}{l}\text { Registration } \\
\text { details (skills on } \\
\text { offer, mentor } \\
\text { offers) }\end{array}$ & $\begin{array}{l}110 \\
\text { people }\end{array}$ & 81 people & Blog \\
\cline { 2 - 5 } 36-Item Healthy do you feel, RAND & $\begin{array}{l}\text { About each group } \\
\text { (who, problem, } \\
\text { innovation) }\end{array}$ & $\begin{array}{l}42 \text { people } \\
\text { in 7 } \\
\text { groups }\end{array}$ & $\begin{array}{l}\text { 27 people } \\
\text { in 6 } \\
\text { groups }\end{array}$ & Evaluation \\
\cline { 2 - 5 } $\begin{array}{l}\text { Questionnaire Items (Rand } \\
\text { Health, 2016) }\end{array}$ & $\begin{array}{l}\text { Photos of group } \\
\text { work }\end{array}$ & 33 & 31 & Twitter trail \\
\cline { 2 - 5 } $\begin{array}{l}\text { 2 Patient assessment of care } \\
\text { received for a long term health } \\
\text { issue (Glasgow et al., 2005) }\end{array}$ & interview sets & 11 & 5 & $\begin{array}{l}\text { Observations } \\
\text { and researcher } \\
\text { reflections }\end{array}$ \\
$\begin{array}{l}\text { 3 How confident are you about } \\
\text { your health (Smith, Wallston, \& } \\
\text { Smith, 1995) }\end{array}$ & & & & \\
\hline
\end{tabular}

\section{Table 1: Data sources}

The questionnaires were designed to elicit information about chronic conditions of participants ('How healthy do you feel' questionnaire) and perceptions of what it is like to be a patient in the NZ health system ('Patient assessment of care received' questionnaire) and how a person was coping with a long term health issue ('How confident are you about your health' questionnaire). It was assumed that the hackathon topic of 'solving self-care' would attract people with long term health issues that they wanted to solve, or at least influence solutions because of a lived experience with a health issue.

The registration form was designed to ask for name (stripped for research purposes, but used for registration and name badge), day job, skills offered for use at a hackathon, offer to be mentor, offer to work in a team/group, dietary requirements (for catering purposes and not used for the research). The registration data were analysed for skills patterns.

People took photos of one another and tweeted about the event using them, and the hackathon host (KD) took photos for her blog and research. A professional photographer donated his time and skill and took 186 photos of the Sunday presentations and judges announcing the winner for the 2015 event. KD took 119 photos of the 2016 presentations and judging.

There were two self-serve interviews: (1) Working in my group, and (2) Our innovation in 2050. Participants were alone when completing each interview, which took between five and ten minutes each to complete. Table 2 contains the interview questions. 


\begin{tabular}{|c|c|}
\hline Interview 1: Working in my group & Interview 2: Our innovation in 2050 \\
\hline $\begin{array}{l}\text { Please start the recorder and tell us about your } \\
\text { day job and why you decided to come to this } \\
\text { hackathon, i.e. what work do you do and what } \\
\text { are you hoping to do at this hackathon? }\end{array}$ & $\begin{array}{l}\text { Please start the recorder and tell us about your } \\
\text { day job and what idea your group is working on. } \\
\text { If you have a long term health issue, please } \\
\text { briefly describe it. }\end{array}$ \\
\hline $\begin{array}{l}\text { What idea is your group working on? } \\
\text { Why did you choose that team? }\end{array}$ & $\begin{array}{l}\text { Tell us about a health experience you've had } \\
\text { that influences how you're thinking about your } \\
\text { group's idea? }\end{array}$ \\
\hline $\begin{array}{l}\text { Was there another idea you were also interested } \\
\text { in? If so, why did you not join that team? }\end{array}$ & $\begin{array}{l}\text { If you don't have a health issue, what brought } \\
\text { you to this hackathon? }\end{array}$ \\
\hline $\begin{array}{l}\text { From your point of view, what are the people in } \\
\text { your group contributing to the development of } \\
\text { the group's idea? For example, what are their } \\
\text { day jobs and what roles are they playing in the } \\
\text { group? }\end{array}$ & $\begin{array}{l}\text { How do you imagine how healthcare will work } \\
\text { in } 2050 \text { ? } \\
\text { If there were no risk of failure, how would your } \\
\text { team's idea have to change to be useful in } 2050 \text { ? }\end{array}$ \\
\hline $\begin{array}{l}\text { What is the most important aspect of the } \\
\text { solution you're working on? }\end{array}$ & \\
\hline $\begin{array}{l}\text { If your solution gets finished and people are able } \\
\text { to use it one day, how and where would people } \\
\text { use it? }\end{array}$ & \\
\hline $\begin{array}{l}\text { If you remove an aspect of your solution that } \\
\text { stops it from working, what would that aspect } \\
\text { be? }\end{array}$ & \\
\hline What does success look like for your team? & \\
\hline
\end{tabular}

\section{Table 2: Self-serve interview questions}

We chose self-administered (self-serve) structured interviews to explore the hackathon experience. Self-administered validated interviews have been designed for witness statements from children (Gawrylowicz, Memon, \& Scoboria, 2014), but self-administration usually applies to questionnaires. Instructions are given to the respondent who then records answers to structured questions. Since self-administered interviews are not frequently reported in the literature, we used the strengths and weaknesses of self-administration for questionnaires to assist our decision to use self-administered interviews. Self-administration is perceived to improve the honesty and candidness of responses in the absence of the interviewer (Rodriguez, Sana, \& Sisk, 2015). The tone of hackathons is usually voluntariness and generosity; we wanted to preserve this tone in the ethics of our data gathering. The self-organising group dynamic that typically has fragile commitment that changes over the weekend (Jones et al., 2015), influenced our decision to set up a quiet and private interview space, invite people to complete the interviews at a time that suited them during the hackathon, and be available to support them if they had any questions. Self-administered interviews and questionnaires alike, especially if voluntary, are at risk of attracting fewer responses than assisted questionnaires and in-person interviews (Rodriguez et al., 2015). The benefits of honesty and openness in a voluntary activity that fitted the dynamics of a hackathon weekend outweighed the risk of low response rates. Triangulation and the use of thick description connected the data from many sources to create a rich picture.

People responded to the interview invitation as per Table 3. It was difficult for people to set aside time at the hackathon to complete the interviews. The first half of the weekend was too early for answers to our questions, and the commitment to the competition was so strong from 
the Saturday afternoon onwards that people only set aside time just before Sunday lunch and after the judging session to complete some interviews.

\begin{tabular}{|l|c|c|c|c|}
\hline Interview & \multicolumn{2}{|c|}{ 1: Working in my group } & \multicolumn{2}{c|}{ 2: Our innovation in 2050 } \\
\hline Year & 2015 & 2016 & 2015 & 2016 \\
\hline Number of interviews & 9 & 0 & 11 & 5 \\
\hline
\end{tabular}

Table 3: Uptake of self-serve interviews

The blog (Day, 2015) recorded aspects of the hackathon, particularly the judges' choice of winner, the People's Vote after the hackathon, and any stories and photos that were written about. The Twitter trail for both events contained comments and photos that could be used for understanding group dynamics and processes. Researcher observations were noted in field notes.

The data analysis was primarily qualitative. The registration data were analysed to find patterns of skills for the hackathon as a whole. They were also used to attribute skills (as defined by day jobs) to groups to demonstrate how skill/role mixes gravitated towards different topics associated with the groups. The photos were visually analysed to determine group dynamics and progress at certain times during each event. The blog was analysed to compare and contrast what the groups worked on during the two events. The content of researcher observation notes was analysed for references to how the groups worked and how the dynamics changed over time during the two events.

\section{Findings}

\subsection{What they achieved}

Most of the 2015 problems were presented by clinicians, i.e. paediatrician (winning group's leader), pharmacists, a GP, hospital doctor, and LabSmart was presented by a primary service's information systems manager. The spread was equal in 2016, where three of six groups were led by a public health professional (winning group leader), a pharmacist, and a clinical researcher. The balance were led by a postgraduate health informatics student, a person with a rare genetic disorder, and the general manager of a software company. Table 4 indicates the problems and solutions worked on in groups. All the solutions required data collection from patients, and use of data by patients and their healthcare professionals. Not all the solutions met the brief about self-care, but they all appear to meet the requirements of participatory medicine, e.g. citizen feels in charge of their health by gathering and using data.

\begin{tabular}{|c|c|}
\hline 2015 & \\
\hline Group name & Problem and solution \\
\hline $\begin{array}{l}\text { Fight the fever } \\
\text { (winner) }\end{array}$ & $\begin{array}{l}\text { Problem: Reducing occurrence of rheumatic fever by increasing compliance } \\
\text { of secondary prophylaxis. } \\
\text { Solution: A mobile app, encouraging self and whanau management (Whanau } \\
\text { Ora approach (Ministry of Health, 2015)). }\end{array}$ \\
\hline Talking pillbox & $\begin{array}{l}\text { Problem: Medication adherence for visually impaired people and those with } \\
\text { language barrier. } \\
\text { Solution: Talking label. Simply press the label to hear your name, drugs, and } \\
\text { instruction from the pharmacist in the language you understand. }\end{array}$ \\
\hline Read my drugs & $\begin{array}{l}\text { Problem: Poor understanding of medical labels due to bad vision, language } \\
\text { barrier, poor literacy. } \\
\text { Solution: QR codes printed on medication labels at pharmacy. Patient scans } \\
\text { the QR code using our app on their smart phone and will be presented with an } \\
\text { enlarged version of the label, translated into their preferred language and with } \\
\text { the option for the medication instructions to be read out audibly. }\end{array}$ \\
\hline
\end{tabular}




\begin{tabular}{|c|c|}
\hline 2015 & \\
\hline Lab Smart & $\begin{array}{l}\text { Problem: Ensuring Type } 2 \text { Diabetes patients get the lab requisition forms and } \\
\text { results prior to their } 3 \text {-monthly GP visit to collect their medication } \\
\text { prescription so that they can ask questions and be responsible in managing } \\
\text { their health. } \\
\text { Solution: Automate the form from GP systems (validated by GP) to the } \\
\text { patient by email in the short term and directly to the lab and notification to the } \\
\text { patient in the long term. Similar process (long term) for: lab results, medicine } \\
\text { prescription, referral to podiatrist. }\end{array}$ \\
\hline Got Pain & $\begin{array}{l}\text { Problem: Self-management of angina chest pain. Aim to improve } \\
\text { empowerment, conduct remote monitoring, reduce hospital admissions. } \\
\text { Solution: All with binary options based on American Heart Association } \\
\text { guidelines and algorithm. }\end{array}$ \\
\hline Hunger Minder & $\begin{array}{l}\text { Problem: Global misunderstanding of the correct cues for hunger; physical } \\
\text { hunger is not easily recognised. } \\
\text { Solution: HungerMinder: A mobile phone App designed to give people the } \\
\text { ability to recognise and be aware of hunger symptoms and to support them in } \\
\text { their ability to make better eating decisions meal by meal. }\end{array}$ \\
\hline $\begin{array}{l}\text { Healthy me, } \\
\text { healthy you }\end{array}$ & $\begin{array}{l}\text { Problem: Information mismatch between information and support people } \\
\text { typically receive (too little, too much, wrong level) after a consultation of } \\
\text { admission to hospital and what they want or need to self-care optimally. } \\
\text { Solution: A wiki-style mobile app that can tailor information and resources to } \\
\text { needs of patient and they can choose what and when to access it. This includes } \\
\text { a Top Tips Library where patients and providers can share through a vetted } \\
\text { approved process their ideas and top tips for living well with a range of } \\
\text { conditions and issues, building an interactive community of interest. }\end{array}$ \\
\hline 2016 & \\
\hline $\begin{array}{l}\text { Project Bump } \\
\text { (winner) }\end{array}$ & $\begin{array}{l}\text { Problem: Paper pamphlets with no way of measuring of health literacy } \\
\text { Solution: A web based mobile friendly platform scalable to long term } \\
\text { conditions and the global market, an immersive experience for users }\end{array}$ \\
\hline LOOP & $\begin{array}{l}\text { Problem: Patients not being fully informed of their test results of } \\
\text { understanding what the results mean. } \\
\text { Solution: Website/app which allows patient to track the full journey of their } \\
\text { test results. Also incorporates decision support algorithm which provides } \\
\text { patients with a suggested action to follow up their result. This will also boost } \\
\text { health literacy. }\end{array}$ \\
\hline Divert Myself & $\begin{array}{l}\text { Problem: Lack of self-monitoring and self-management tools for Diverticular } \\
\text { Disease } \\
\text { Solution: Interactive mobile application for self-management, monitoring } \\
\text { and wellbeing of people who have a lived experience of Diverticular Disease }\end{array}$ \\
\hline medLOOK & $\begin{array}{l}\text { Problem: Poor health literacy, high medication error, and poor medication } \\
\text { adherence to prescriptions } \\
\text { Solution: Care support applications such as medication reminders, } \\
\text { medication tracking, utilizing a crowd sourced (from pharmacists) medication } \\
\text { database }\end{array}$ \\
\hline HealtheID & $\begin{array}{l}\text { Problem: Lack of verified and credentialed authentication available to } \\
\text { systems which operate in health care } \\
\text { Solution: Verified ID, linked to credentialing available to systems as a service }\end{array}$ \\
\hline dotdotdot & $\begin{array}{l}\text { Problem: People with rare conditions take longer to diagnose. They find it } \\
\text { difficult to know what to expect (symptoms to diagnosis, surgeries, jargon). } \\
\text { Solution: Smart profiles in which user comparisons can be make against } \\
\text { aggregated data to match profiles. }\end{array}$ \\
\hline
\end{tabular}

Table 4: The problems and solutions of the groups for the two hackathons

\subsection{Who came and what they contributed}

Hackathons are about people, the problems they want to solve, and the skills and experience they bring to the solutions they choose to work on. As per Table 1, there were 110 registrations for the 2015 hackathon and 81 in 2016. The questionnaires revealed a health profile, and the registration data provided a day jobs and skills profile. 


\subsubsection{Health profile}

From the questionnaires we determined that most of the 53 respondents (from both years) felt healthy; were confident about their health and how they managed it; $60 \%$ of respondents had long term health issues; and 36\% knew someone with a long term health issue. They listed a variety of conditions ranging from food allergies to overweight, mental health issues, diabetes, and glaucoma, among others. In response to the positive questions in the 'How confident do you feel' questionnaire, the respondents were mostly positive and felt confident about managing their health (Figure 1). This was supported in the questions that were negatively framed. $56 \%$ of the participants were in the age range of $18-39$, one person was 15 years old, no-one was older than 69 , and $53 \%$ were female.

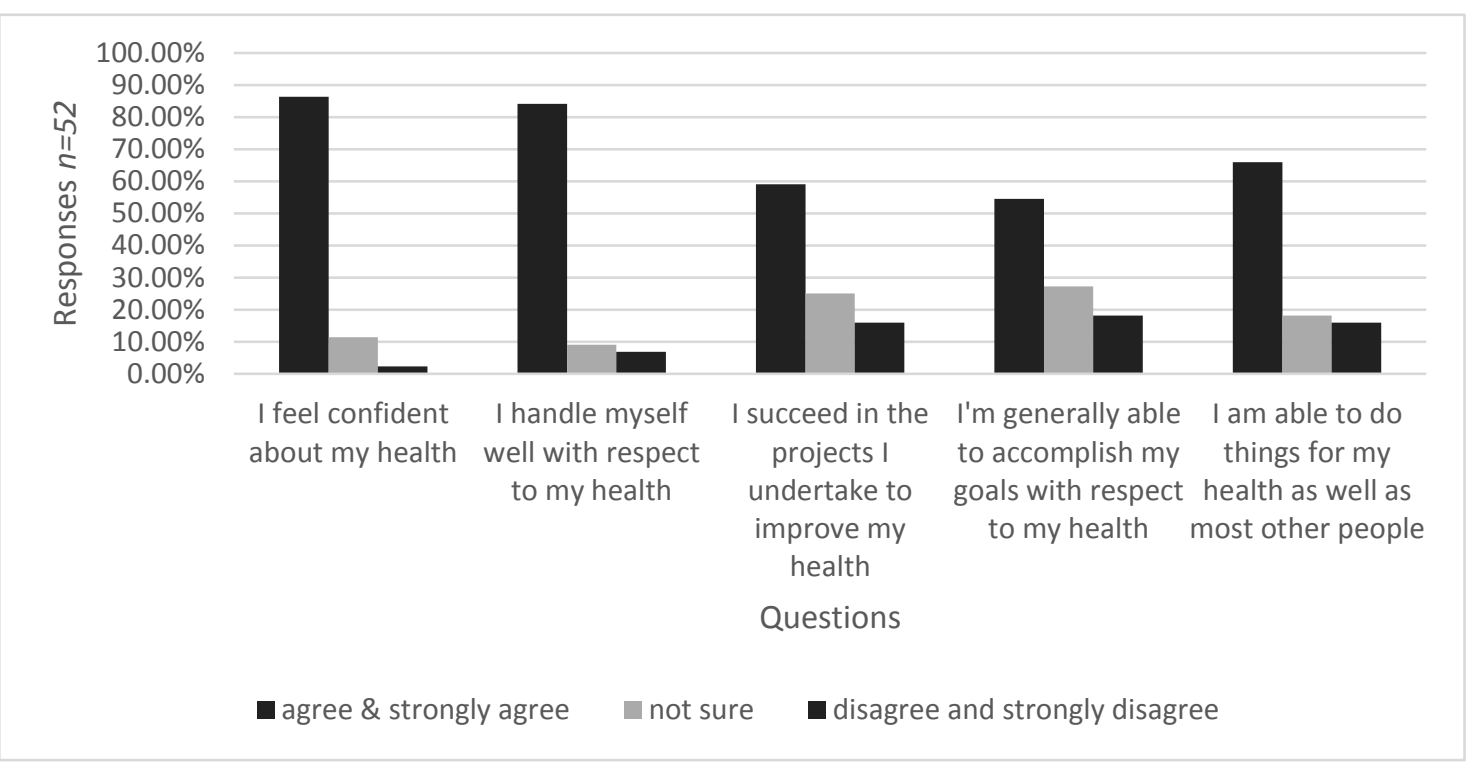

Figure 1 'How confident do you feel about your health' questionnaire

There were only eight responses to the other two questionnaires. Seven respondents indicated that they felt well and were mostly satisfied (agree rather than strongly agree) with the health services that they used. One person felt let down by the health system, which was confirmed in volunteered discussion during the course of the 2015 hackathon.

This health profile is confirmed in the interviews. Since the interviews were anonymous we cannot match them to the questionnaire respondents. The question, 'Tell us about a health experience you've had that influences how you're thinking about your group's idea' revealed that some people came to the hackathon with an agenda to solve a personal health issue, while others did not link their health experience to their hackathon intentions. One person indicated that the process of lab tests and GP (general practitioner) visits was not logical - personal experience made it illogical to visit the GP to discuss diabetes progress if the lab tests are done after the appointment. Another person had lost a significant amount of weight and became interested in learning how the body signals hunger, hence her interest in the Hunger Minder group. Someone from the Fight the Fever group was taking medications regularly and, although was doing well, was interested in helping other people who may struggle to take their medications regularly. Three participants from different groups did not have a long term health issue, and indicated that there was no personal experience that influenced their thinking. A doctor who had had an injury resulting in surgery and hospitalisation indicated that the experience had influenced her thinking, saying, 'And when I became a patient I was so surprised at the incredible disempowerment I felt.' She wanted to influence the development of a product that met the needs she had experienced, and from the citizen's point of view. 


\subsubsection{Day jobs and skills profile}

Their 'day jobs' and the skills they offered at the hackathon were varied. Both hackathons attracted people whose roles fitted into groups that repeated in 2016. The types of groups and the differences between the two hackathons are shown in Figure 2.

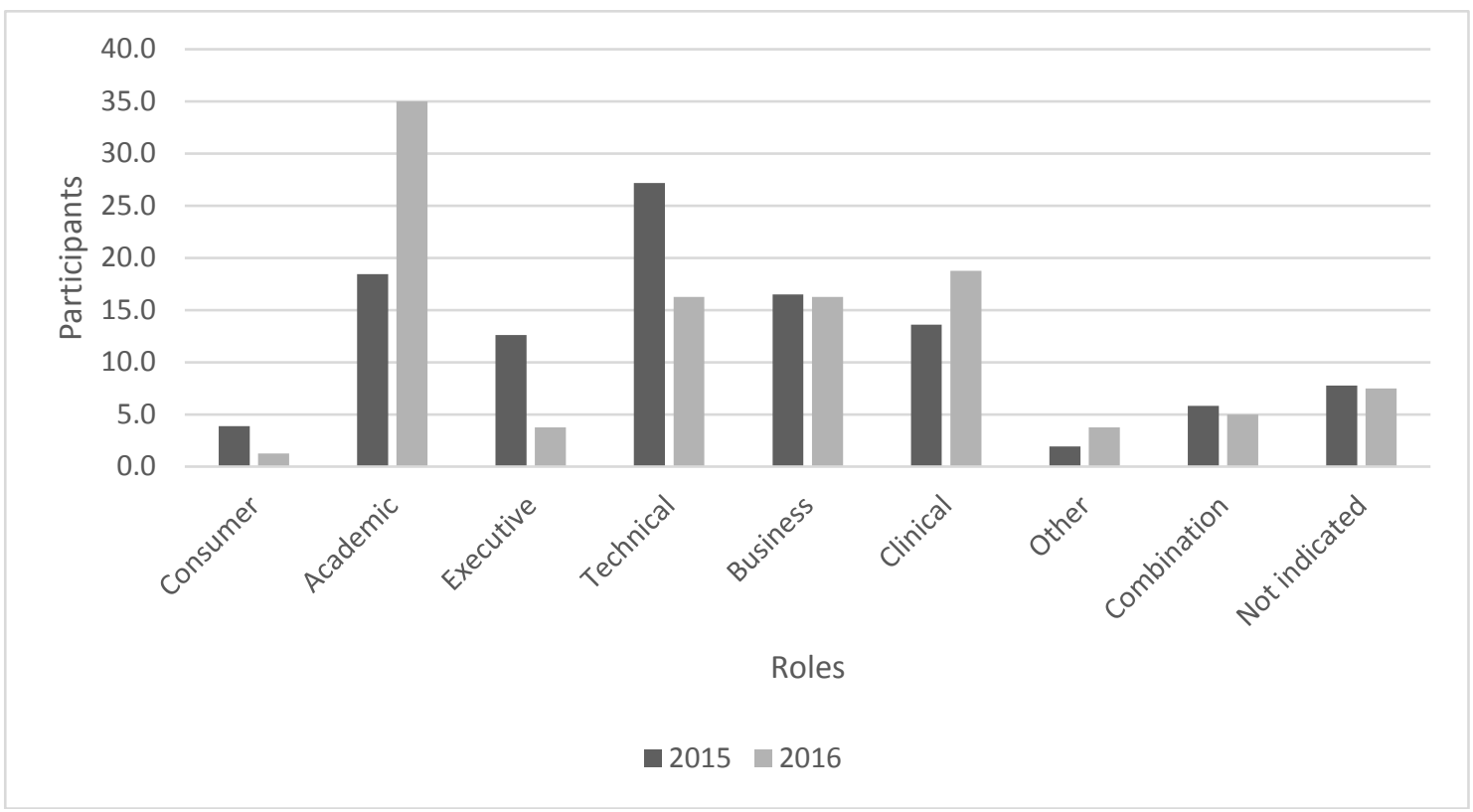

Figure 2: Day jobs of people who registered

The business and clinical roles show little difference between 2015 and 2016. The high number of academic people registering for the 2016 hackathon is a result of strong marketing at universities that did not happen in 2015. The 2015 hackathon's date had been set for before semester because the campus would have unused space that the hackathon could take advantage of. We realised that students should have been given an opportunity to attend the hackathon, and so the 2016 date was set for three weeks after the beginning of semester to include students. More technical people registered in 2015 and slightly more clinical people registered in 2016. This resulted in some 2016 groups not having a software developer to assist them.

Some roles on the registration forms did not fit into any of the groupings that occurred from analysing the registration data, and they formed the groups 'other' and 'combination'. The 'other' group for 2015 consisted of a student working part time in a job unrelated to health care, and a journalist. This group in 2016 consisted of a graphic designer, a forecourt attendant at a fuel station, and a glass installer. The 'combination' group in 2015 was made up of four people with previous clinical roles (a nurse, two pharmacists, and a doctor), who were now doing user experience design, business analysis, decision support systems, and software development respectively. Two people had two concurrent roles; one was a company director and part time physiotherapist and the other was IT support and planetarium director. In 2016 this group of four people each had two concurrent roles. Two were medical education fellows and RMOs (Registered Medical Officers enrolled in specialisation study programme), one was a developer and a university student, and the other was a computer programmer who is also doing a Master of health informatics.

The day jobs showed up in the groups unpredictably as can be seen in Table 5. Each person chose to join a group on the basis of their interests and what they felt they could contribute. The mean number of people in a group was 6 , and the mode 5 . Group size ranged from 2 to 10 . The smallest groups could not leverage group dynamics, and the largest groups ( 8 and above) struggled with complex group dynamics. The two winning groups, Fight the Fever and Bump, had six and seven members respectively, close to the mean group size. The success of this group size (6-7) is consistent with recommendations in Raatikainen et al (2013). 
The leaders of the groups had a vested interest in their group's progress because the group's work was based on those people's ideas pitched on the Friday. In the interviews about their innovation in 2050, those who were group leaders indicated that their idea would have solved the problem it was currently responding to and therefore would not exist in 2050. In contrast software developers asked to be assigned to groups, as indicated by a young coder saying, 'Tell me which group to join so that I can write code.'

\begin{tabular}{|c|c|c|c|c|c|c|c|c|c|}
\hline 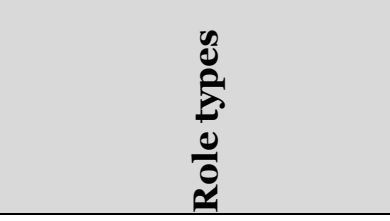 & 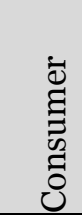 & 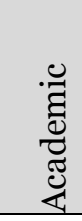 & 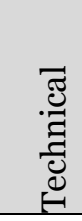 & 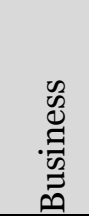 & 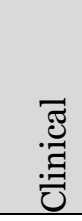 & $\begin{array}{l}\vec{\Xi} \\
\overrightarrow{0}\end{array}$ & 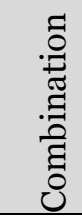 & 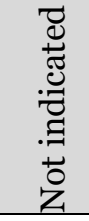 & 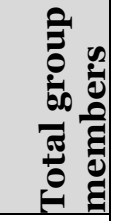 \\
\hline \multicolumn{10}{|l|}{2015} \\
\hline Fight the fever & & & 1 & 2 & 1 & & & 2 & 6 \\
\hline Talking pillbox & & & 1 & & 1 & & & & 2 \\
\hline Read my drugs & & 1 & 1 & 1 & & & 1 & & 4 \\
\hline Lab Smart & & 1 & 5 & 1 & & & & 1 & 8 \\
\hline Got Pain & & 2 & 2 & & 3 & & & & 7 \\
\hline Hunger Minder & & 3 & 3 & 3 & 1 & & & & 10 \\
\hline Healthy me, healthy you & 1 & 3 & & 1 & 2 & & 1 & 1 & 9 \\
\hline \multicolumn{10}{|l|}{2016} \\
\hline Bump & & 2 & 1 & 2 & 1 & 1 & & & 7 \\
\hline LOOP & & 3 & 1 & 1 & & & & & 5 \\
\hline Divert Myself & & 2 & & 2 & & & & 1 & 5 \\
\hline medLOOK & & & 2 & & 2 & & & & 4 \\
\hline HealtheID & & & 1 & 3 & & & & 1 & 5 \\
\hline dotdotdot & & & & 2 & & & & & 2 \\
\hline
\end{tabular}

Table 5: Roles in the groups

Not all people who registered answered the question in the registration form about the skills they brought to the hackathon. Several left the answer blank, 17 indicated their role (e.g. nurse, doctor, pharmacist, software developer), seven stated their interest (present an idea; interest in telemonitoring, neuroscience, health promotion and behaviour change, working on an interactive app, 'bring innovative solutions to health care'), 24 described experience, and 48 listed skills. The skills fell into four themes: clinical (e.g. medical knowledge, self-care programme development), IT (e.g. software development, database analysis), business (e.g. process analysis, patent, marketing), and design (e.g. creative thinking, user experience design), as can be seen in Table 6. 


\begin{tabular}{|l|c|c|c|c|}
\hline & Clinical & IT & Business & Design \\
\hline Knowledge & 9 & 3 & 12 & 7 \\
\hline $\begin{array}{l}\text { Patient focussed } \\
\text { skills }\end{array}$ & 7 & & & 3 \\
\hline Analytical skills & $\mathbf{1}$ & $\mathbf{2}$ & $\mathbf{1 1}$ & \\
\hline $\begin{array}{l}\text { Software design } \\
\text { skills }\end{array}$ & & 25 & & 4 \\
\hline Perspective & $\mathbf{2}$ & $\mathbf{2}$ & 7 & 2 \\
\hline
\end{tabular}

Table 6 Thematic breakdown of skills listed in registration form

These themes in turn fell into five types of skills. People brought knowledge (e.g. medical/business/technical/health informatics knowledge) and their own perspective (e.g. junior doctor, project management, creative thinker). There is no overlap between clinical and business people with software designers, as would be expected. The overlap between clinical and design skills took the form of user experience design and patient centred design.

\subsection{Why they came and how their health issues influenced innovation (or not)}

The reasons interviewees gave for attending the hackathon were mostly about meeting people and seeing how they use their different skills to solve problems. They felt they had something to contribute but did not frame their contribution as citizens who access and use healthcare services. One person encapsulated the hackathon experience, saying,

'And I thought, well I first wanted to see how it works, what it is, how I could have fun with unknown people suddenly forming into a team and trying to develop something in this short time frame. And to see if there is, if it can really be done.'

The interviewees described their groups' dynamics by privileging certain roles, depending on the role and perspective of the person talking. Clinicians privileged clinical contributions and then indicated that they had attended the hackathon to leverage technical skills. A developer from the same group talked first about other developers and technically skilled people and then about clinicians. This implies that people work and think from their perspective first, and if not reminded of other perspectives may overlook the role of people living with long term health issues in innovation development. Of the interviewees working in the LabSmart group, one person did not have a health issue, one had arthritis, and the other had type 2 diabetes. The way the two with health issues talked about their contribution to the group's work was couched in personal experience tones rather than the skills they brought to the group's solution.

The attraction of the hackathon was not about the event's theme, but an opportunity to develop something that put citizens in 'the driver's seat' (Frydman, 2010). One group ignored the brief and focussed on a problem that their leader was passionate about, e.g. HealtheID, arguing that big data requires a different approach to identity authentication and management, especially if citizens collect, analyse, and use their own data, or personal data clouds as described by Flores et al (2013).

The question about what healthcare could be like in 2050 raised insights such as the ability to use technology to make healthcare processes, activities, and decision making much more transparent. Some participants focused on efficiency gains, reduction in costs of care, automation, and the use of more sophisticated technology to simplify care and make it easier to access. Others indicated that citizens should take more responsibility for their health, be more accountable, and become more involved.

\subsection{The hackathon process and dynamics}

Ideas that were pitched on the Friday evening ranged from well-formed, thoughtful innovations, to fuzzy possibilities. Fifteen ideas were pitched in 2015, one person told a story about a catastrophic stroke she had experienced and offered a patient's perspective, and one 
person simply offered software development skills saying that she had no healthcare experience but wanted to help. In 2016 seven people pitched ideas, and no-one took the stage for other reasons.

There appeared to be a pattern of interpersonal dynamics at both hackathons that contributed to the spirit of the 'hack way' as described by Chowdhury (2012) and described as social benefits by Raatikainen et al (2013). People arrived on the Friday, keen to share their ideas and listen to others. The dynamics shifted during the weekend as described by Jones (2015), as people explored the ideas of others, tentatively indicated interest, which grew into tentative commitment. By Saturday morning the commitment was confirmed, as noted in a mentor's Twitter comment, 'Day 2 groups formed - stormed and in deep'.

In both hackathons there was a group that completely restructured the next day (Talking Pillbox and LOOP). In 2015 several pharmacists pitched ideas about people taking their medicines reliably and with insight. One group formed to address this problem, but two members of the group disagreed with the proposed solution and formed a new group. LOOP had a good foundation but some determined that it needed to change in focus to meet the brief of the hackathon topic. By noon on Saturday these two groups had appeared to resolve their differences and were committed to their collective goals. This dip in morale and recovery confirms this finding of previous hackathon case studies (Raatikainen et al., 2013). All the groups spent the morning brainstorming and exploring a broad range of ways to solve the problem they had chosen. Mentors challenged the content that was emerging from the brainstorming activities. At this point, all the groups demonstrated a shift in the problem definition (it was less clear than in the pitching session), and possible solution (new ideas were being explored).

Groups were 'failing early, and pivoting fast' as described by DePasse et al (2014), changing direction to what could be more successful. The challenges from the mentors appeared to unsettle group members. There was lively debate. Conflicts in perspective, content, and purpose surfaced and groups attempted to resolve them by accommodating, modifying, and/or discarding suggestions. Mentors focussed groups on what their minimum viable product would be on Sunday afternoon, which appeared to sharpen the intensity of the groups' activities. The challenge about how they planned to commercialise their product appeared to increase their anxiety about being able to complete a prototype in time. One participant commented on Twitter saying, 'Was a super stressful weekend but extremely rewarding!' The challenges did not appear to divert them from their goals, but did help them pivot to more useful ways of achieving their goals.

By the Saturday evening the groups had become quiet and there was evidence of hard work in Post-IT notes and butcher's paper with brainstormed ideas posted on the walls. Some groups were using 'lean canvas' charts (supplied by a mentor). The white boards had mind maps, diagrams, and notes, which had been written and rewritten during the course of the day. Group members took on individual tasks or paired up to complete tasks.

On the final day, declining mentor interactions, and with the requirements relatively stable, groups focussed on refining their prototypes and presentations. Groups appeared to resent interruptions and were focussed on single-mindedly completing their minimum viable product sufficiently to present it to the judges after lunch. The stress was palpable until after the winners were announced by the judges.

\section{Discussion and conclusion}

Our research question was, 'How do the design features of health hackathons contribute to participatory medicine?' We hosted two hackathons titled, 'Health Hackathon: Solving Selfcare' and gathered data to form a thick description of how health hackathons enable participatory medicine as a form of participatory information systems design.

People did not register for the hackathon on the basis of a lived experience with a long term health issue. However, many of those who attended did have personal experience of a health 
issue or knew someone who had experienced a long term health issue. Those who responded to the questionnaires were confident about their ability to take care of their health, were generally satisfied with the healthcare services they received, and felt healthy. The interviews revealed that people did not specifically use their health issue to influence how a group worked on a solution but found that the influence was present in their contributions and decisions. Their day jobs and skills mixes mirrored those that are carefully selected in the usual information systems design process, i.e. healthcare stakeholders include clinicians and consumers and the rest of the team consists of developers and analysts. In contrast, hackathon design teams form spontaneously. It is not typical for consumers who have long term health issues to be included in software development requirements gathering or be directly involved in the development process (Nunes, Verdezoto, Fitzpatrick, Kyng, Grönvall, et al., 2015). Hackathons offer an unprecedented opportunity to include citizens and enable them to drive the requirements. Citizens being in charge of their health and how they use services is integral to participatory medicine (Flores et al., 2013; Hood \& Auffray, 2013), and hackathons offer opportunities for this kind of citizen investment in their own health.

Hackathons are a radical departure from standard information systems design processes. Requirements gathering, iterative design to meet the requirements, and testing are not part of the hackathon process. That is not to say that the process is at odds with information system development. We propose the contrary that hackathons, and their focus on the minimum viable product, are complimentary to newer agile methods in development with a focus on synergy between stakeholder groups and creativity. Most of the problems and associated solutions proposed at our hackathons represented pain points experienced by clinicians, e.g. Fight the Fever was presented and led by a paediatrician, and Hunger Minder arose from research conducted by a general practitioner. The self-organised groups, however, were not predetermined and people became committed to them out of either a personal experience of the problem or an interest in it (usually a personal or clinical interest), or to use skills to build a solution. Anyone could join a group. People described the group dynamics according to their own world view, rather than privileging one person's skill set or point of view or requirements over another. All who joined a group found meaningful ways to contribute to the group's product design. They brought their own perspective and privileged that perspective. Typically clinicians are considered to be end users (B. Rahimi \& Vimarland, 2007). In hackathons citizens and clinicians share the end user role.

The minimum viable products of software that emerged from our health hackathons were designed for data collection about health issues and the associated self-care activities and requirements. It appears from our findings that hackathon members were not concerned about the personal data cloud that would be collected as a result of their solutions. In contrast, one group, HealtheID, was concerned about interoperability issues, and identity authentication and management for big data collections from multiple sources. However, even the judges did not perceive this new role of identity management and disqualified the team because they did not meet the brief of self-care. The participatory medicine potential of big data and personal data clouds as described by Flores et al (2013) was not perceived by anyone other than the HealtheID group.

The solutions that were presented to the judges in both hackathons relied heavily on mobile phone app designs. Clinicians use smartphone apps for drug guides, medical calculations and billing (Franko \& Tirrell, 2012). Apps are also available for citizens to use for monitoring aspects of health and wellbeing, and the most commonly addressed health conditions are diabetes, diet and exercise, smoking cessation and mental health (Boulos, Brewer, Karimkhani, Buller, \& Dellavalle, 2014; Martínez-Pérez, de la Torre-Díez, \& López-Coronado, 2013) and the most common intervention strategy is tracking. Amongst apps used to monitor health, Bennett (2015) notes the difference between apps that protect health and encourage good health behaviours and those that purport to monitor physical parameters and possibly detect the presence of disease. Since the topic of our hackathons was self-care, the latter group of apps featured. 
It is not surprising that mobile phone apps lend themselves to the hackathon environment, where rapid development of a minimum viable product and intensive work on construction of a solution constrain the scope of and platform for a solution. It is frequently stated in the literature that there is a glut of health apps on the market, and further that there is a significant gap between consumer products and scientific validation with developers seeing success in terms of revenue rather than improvement in patient outcome (Boulos et al., 2014). These apps are often developed without citizen and/or clinician involvement and are often not evidence based. With this problem in mind Stoyanov et al (2015) devised a score card to empirically evaluate the quality of health apps. This comprehensive tool includes issues of design, security, functionality and quality of information. Beyond app quality, the risk that poor apps pose to users was considered by Lewis and Wyatt (2015) who developed an algorithm for statistically modelling the risks of adverse events associated with using health apps. The need for consumer and patient and practitioner involvement identified by Krebs et al (2004) lends weight to the hackathon approach. We recommend that future hackathons make such evaluation tools available to enable groups to think through their solution in the context of safety from the outset, and how much future work is needed to prevent possible adverse events.

The group dynamics shifted during the weekend from enthusiastic interest in a topic, through the 'forming, storming, norming, and performing' phases from Tuckman's model of group dynamics (Bonebright, 2010). Commitment to the group's final minimum viable product grew as time passed, and the intensity of the contributions and discussions grew until they were ready to present to the judges. Challenging discussions from mentors at the beginning were welcomed but interruptions were resented in the hours preceding the judging. The mentors played a crucial role in focussing the groups, and challenging individuals to think and work creatively. This is supported in the literature, where Trainer et al (2014) have indicated that without mentors novice groups of developers and innovators would flounder. A hackathon is a micro-network of people from different walks of life, some of whom have experience of long term health issues, which influence how they think and act about solutions to problems pitched by others. The hackathon gives citizens, the 'practice team' of clinicians and managers, and software developers space to create innovative solutions to problems. The group dynamic shifts as different aspects of the solution are developed, and the citizen has the opportunity to be in the driving seat' as and when necessary.

There were some limitations to this study. The events were limited to a weekend each, with small numbers of people contributing to the questionnaires and self-serve interviews. The hackathon process limited the number of opportunities for people to respond to the interviews and questionnaires. Consequently, there was a low response rate and the interviews were inconsistently completed. To ensure rigour we used multiple methods to derive a thick description as outlined by Geertz (1994) and triangulated data that overlapped between methods (Morse, 2015).

Hackathons add a dimension to traditional participatory information systems design processes. Due to the short time for developing a response to a problem (one weekend) the usual rigour is not present in terms of requirements gathering before software development and testing and evaluation afterwards. This should fall into the pre- and post-hackathon periods described by Komssi et al (2015). Hackathons offer opportunities for citizens with long term health issues to share the end-user role that clinicians usually occupy, or to simply occupy the role fully by providing solutions to their own pain points, thereby taking charge of their own health (Auffray et al., 2010; Flores et al., 2013; Hood \& Auffray, 2013) or occupying the driver's seat of their healthcare situation (Frydman, 2010). Hackathons offer opportunities for information systems development in creating the future of healthcare, as described by Swan (2012). The big data that results from participatory medicine becomes part of public and population and personal health in ways not yet perceived, and citizens take charge of their health in unprecedented ways using solutions arising from prototypes developed collaboratively in hackathons. 


\section{References}

Andersen, T., Bansler, J., Kensing, F., Moll, J., \& Nielsen, K. D. (2014). Alignment of Concerns: A Design Rationale for Patient Participation in eHealth. In R. H. Sprague (Ed.), 2014 47th Hawaii International Conference on System Sciences (pp. 2587-2596).

Angelidis, P., Berman, L., Casas-Perez, M. d. l. L., Celi, L. A., Dafoulas, G. E., Dagan, A., Lopez, J. N., Otine, C., Paik, K, Rojas-Potosi, L., Symeonidis, A. L., Winkler, E. Osorio-Valencia, J. S. (2016). The hackathon model to spur innovation around global mHealth. Journal of Medical Engineering \& Technology, 1-8.

Auffray, C., Charron, D., \& Hood, L. (2010). Predictive, preventive, personalized and participatory medicine: back to the future. Genome Medicine, 2(8), 57.

Ballegaard, S. A., Hansen, T. R., \& Kyng, M. (2008). Healthcare in everyday life: designing healthcare services for daily life. Paper presented at the Proceedings of the SIGCHI Conference on Human Factors in Computing Systems.

Bennett, D. B. (2015). Importance of distinguishing between different types of health app. $B M J, 350$, h2334.

Bonebright, D. A. (2010). 40 years of storming: a historical review of Tuckman's model of small group development. Human Resource Development International, 13(1), 111-120. $10.1080 / 13678861003589099$

Boulos, M. N. K., Brewer, A. C., Karimkhani, C., Buller, D. B., \& Dellavalle, R. P. (2014). Mobile medical and health apps: state of the art, concerns, regulatory control and certification. Online Journal of Public Health Informatics, 5(3) 10.5210/ojphi.v5i3.4814

Bowen, S., McSeveny, K., Lockley, E., Wolstenholme, D., Cobb, M., \& Dearden, A. (2013). How was it for you? Experiences of participatory design in the UK health service. CodesignInternational Journal of Cocreation in Design and the Arts, 9(4), 230-246. $10.1080 / 15710882.2013 .846384$

Bragazzi, N. L. (2013). From Po to P6 medicine, a model of highly participatory, narrative, interactive, and" augmented" medicine: some considerations on Salvatore Iaconesi's clinical story. Patient Preference \& Adherence, 2013 (7), 353 - 359. https://doi.org/10.2147/PPA.S38578

Chowdhury, J. (2012). Hacking Health: Bottom-up Innovation for Healthcare. Technology Innovation Management Review, 2(7), 31.

Cole-Lewis, H. J., Smaldone, A. M., Davidson, P. R., Kukafka, R., Tobin, J. N., Cassells, A., Mynatt, E. D., Hripcsak, G. Mamykina, L. (2016). Participatory approach to the development of a knowledge base for problem-solving in diabetes self-management. International Journal of Medical Informatics, 85(1), 96-103. 10.1016/j.ijmedinf.2015.08.003

Day, K. (2015). Day by Day. Retrieved 5 May 2016, from www.kdayinformatix.wordpress.com

De Silva, D., Burstein, F., Jelinek, H. F., \& Stranieri, A. (2015). Addressing the Complexities of Big Data Analytics in Healthcare: The Diabetes Screening Case. Australasian Journal of Information Systems, 19, S99-S115.

De Silva, D., Burstein, F., Stranieri, A., Williams, K., \& Rinehart, N. (2013). A participatory information management framework for patient centred care of Autism Spectrum Disorder. Paper presented at the 24th Australasian Conference on Information Systems (ACIS).

Dennis, A., Wixom, B. H., \& Roth, R. M. (2014). Systems analysis and design: John wiley \& sons.

DePasse, J. W., Yost, A., Carroll, R., Santorino, D., Ippolito, A., Chu, Z., \& Olson, K. R. (2014). Less Noise, More Hacking: How to Deploy Principles from MIT's Hacking Medicine to 
Accelerate Health Care. International Journal of Technology Assessment in Health Care, 3o(3), 260-264. 10.1017/s0266462314000324

Flores, M., Glusman, G., Brogaard, K., Price, N. D., \& Hood, L. (2013). P4 medicine: how systems medicine will transform the healthcare sector and society. Personalized Medicine, 10(6), 565-576. 10.2217/PME.13.57

Franko, O. I., \& Tirrell, T. F. (2012). Smartphone app use among medical providers in ACGME training programs. Journal of Medical Systems, 36(5), 3135-3139.

Frydman, G. A. (2010). A patient-centric definition of participatory medicine. Retrieved from http://e-patients.net/archives/2010/04/a-patient-centric-definition-of-participatorymedicine.html

Gawrylowicz, J., Memon, A., \& Scoboria, A. (2014). Equipping witnesses with transferable skills: the Self-Administered InterviewC. Psychology, Crime \& Law, 20(4), 315-325. http://dx.doi.org/10.1080/1068316X.2013.777961

Gee, P. M., Greenwood, D. A., Paterniti, D. A., Ward, D., \& Miller, L. M. S. (2015). The eHealth enhanced chronic care model: a theory derivation approach. Journal of Medical Internet Research, 17(4) 10.2196/jmir.4067

Geertz, C. (1994). Thick description: Toward an interpretive theory of culture. In M. Martin \& L. C. McIntyre (Eds.), Readings in the philosophy of social science (pp. 213-231): MIT Press.

Glasgow, R. E., Wagner, E. H., Schaefer, J., Mahoney, L. D., Reid, R. J., \& Greene, S. M. (2005). Development and Validation of the Patient Assessment of Chronic Illness Care (PACIC). Medical Care, 43(5), 436-444.

Hood, L., \& Auffray, C. (2013). Participatory medicine: a driving force for revolutionizing healthcare. Genome Medicine, 5(12), 1-4. DOI: 10.1186/gm514

Jones, G. M., Semel, B., \& Le, A. (2015). “There's no rules. It's hackathon.”: Negotiating Commitment in a Context of Volatile Sociality. Journal of Linguistic Anthropology, 25(3), 322-345. http://dx.doi.org/10.1111/jola.12104

Komssi, M., Pichlis, D., Raatikainen, M., Kindström, K., \& Järvinen, J. (2015). What are hackathons for? IEEE Software, 32(5), 60-67. 10.1109/MS.2014.78

Krebs, A. M., Dorohonceanu, B., \& Marsic, I. (2004). Supporting collaboration in heterogeneous environments. Journal of Management Information Systems, 20(4), 199 - 228. cle: http://dx.doi.org/10.1080/07421222.2004.11045787

Lewis, T. L., \& Wyatt, J. C. (2015). App Usage Factor: A Simple Metric to Compare the Population Impact of Mobile Medical Apps. Journal of Medical Internet Research, 17(8) 10.2196/jmir.4284

Mantzavinou, A., \& Ranger, B. J. (2014). Health hackathons drive affordable medical technology innovation through community engagement. retrieved 6/9/2016 from http://cooperation.epfl.ch/

Martínez-Pérez, B., de la Torre-Díez, I., \& López-Coronado, M. (2013). Mobile Health Applications for the Most Prevalent Conditions by the World Health Organization: Review and Analysis. Journal of Medical Internet Research, 15(6), e120. 10.2196/jmir.2600

Ministry of Health. (2015). Whanau Ora Programme. Retrieved 6/9/2016, from http://www.health.govt.nz/our-work/populations/maori-health/whanau-oraprogramme

Morse, J. M. (2015). Critical analysis of strategies for determining rigor in qualitative inquiry. Qualitative Health Research, 25(9), 1212-1222. 10.1177/1049732315588501 
NHS Hack Day. (2015). Retrieved July, 2016, from http://nhshackday.com/about/team/

NHS, U. (2016). NHS Transformathon. Retrieved 1/9/2016, from http://theedge.nhsiq.nhs.uk/transformathon/

Nunes, F., Verdezoto, N., Fitzpatrick, G., Kyng, M., Gronvall, E., Storni, C. (2015). Self-Care Technologies in HCI: Trends, Tensions, and Opportunities. ACM Trans. Comput.-Hum. Interact., 22(6), 1-45. 10.1145/2803173

Nunes, F., Verdezoto, N., Fitzpatrick, G., Kyng, M., Grönvall, E., \& Storni, C. (2015). Self-care technologies in HCI: Trends, tensions, and opportunities. ACM Transactions on Computer-Human Interaction (TOCHI), 22(6), 33. 10.1145/2803173

Pilemalm, S., \& Timpka, T. (2008). Third generation participatory design in health informatics - Making user participation applicable to large-scale information system projects. Journal of Biomedical Informatics, 41(2), 327-339. 10.1016/j.jbi.2007.09.004

Raatikainen, M., Komssi, M., Dal Bianco, V., Kindstöm, K., \& Järvinen, J. (2013). Industrial experiences of organizing a hackathon to assess a device-centric cloud ecosystem. Paper presented at the Computer Software and Applications Conference (COMPSAC), 2013 IEEE 37th Annual.

Rahimi, B., \& Vimarland, V. (2007). Methods to evaluate health information systems in healthcare settings: A literature review. Journal of Medical Systems, 31, 397 - 432. 10.1007/s10916-007-9082-z

Rahimi, B., Vimarlund, V., \& Timpka, T. (2009). Health information system implementation: a qualitative meta-analysis. Journal of Medical Systems, 33(5), 359. 10.1007/s10916oo8-9198-9

Rand Health. (2016). Medical Outcomes Study: 36-Item Short Form Survey Instrument. $\quad$ Retrieved 5 May 2016, from http://www.rand.org/health/surveys_tools/mos/mos_core_36item_survey_print.htm l

Rodriguez, L. A., Sana, M., \& Sisk, B. (2015). Self-administered questions and interviewerrespondent familiarity. Field Methods, 27(2), 163-181. 10.1177/1525822X14549315

Shelly, G., \& Rosenblatt, H. J. (2011). Systems analysis and design: Cengage Learning.

Smith, M. S., Wallston, K. A., \& Smith, C. A. (1995). The development and validation of the Perceived Health Competence Scale. Health Education Research, 1O(1), 51 - 64.

Stellefson, M. (2013). The chronic care model and diabetes management in US primary care settings: a systematic review. Preventing Chronic Disease, 10, 120180. DOI: http://dx.doi.org/10.5888/pcd10.120180

Stoyanov, S. R., Hides, L., Kavanagh, D. J., Zelenko, O., Tjondronegoro, D., \& Mani, M. (2015). Mobile app rating scale: a new tool for assessing the quality of health mobile apps. JMIR mHealth and uHealth, 3(1)

Swan, M. (2012). Health 2050: The realization of personalized medicine through crowdsourcing, the quantified self, and the participatory biocitizen. Journal of Personalized Medicine, 2(3), 93-118. 10.3390/jpm2030093

Teixeira, L., Saavedra, V., Ferreira, C., Santos, B. S., \& IEEE. (2011). Using Participatory Design in a Health Information System 2011 Annual International Conference of the IEEE Engineering in Medicine and Biology Society (pp. 5339-5342).

Trainer, E., Chaihirunkarn, C., \& Herbsleb, J. (2014). The Big Effects of Short-term Efforts: Mentorship and Code Integration in Open Source Scientific Software. Journal of Open Research Software, 2(1), e18. http://doi.org/10.5334/jors.bc 
Wagner, E. H., Davis, C., Schaefer, J., Von Korff, M., \& Austin, B. (2002). A survey of leading chronic disease management programs: are they consistent with the literature? Journal of Nursing Care Quality, 16(2), 67-80.

Walker, A., \& Ko, N. (2016). Bringing Medicine to the Digital Age via Hackathons and Beyond. Journal of Medical Systems, 4O(4), 1-3. 10.1007/s10916-016-0461-1

Copyright: (C) 2017 Day, Humphrey \& Cockroft. This is an open-access article distributed under the terms of the Creative Commons Attribution-NonCommercial 3.0 Australia License, which permits non-commercial use, distribution, and reproduction in any medium, provided the original author and AJIS are credited.

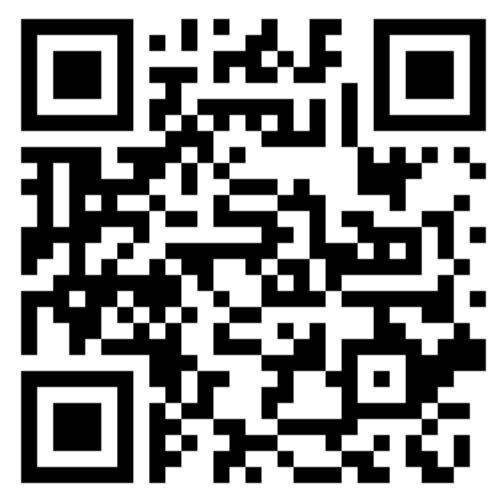

